\title{
Antibody microarray profiling of osteosarcoma cell serum for identifying potential biomarkers
}

\author{
ZI-QIANG ZHU ${ }^{1 *}$, JIN-SHAN TANG ${ }^{2 *}$, DUAN GANG $^{1}$, MING-XING WANG $^{1}$, JIAN-QIANG WANG $^{1}$, \\ ZHOU LEI ${ }^{1}$, ZHOU FENG ${ }^{1}$, MING-LIANG FANG ${ }^{1}$ and LIN YAN $^{1}$ \\ ${ }^{1}$ Department of Orthopedics, The Second Affiliated Hospital of Xuzhou Medical College, Xuzhou, Jiangsu 221006; \\ ${ }^{2}$ Department of Orthopedics, Affiliated Huai'an Hospital of Xuzhou Medical College, \\ Huaian, Jiangsu 223002, P.R. China
}

Received May 17, 2014; Accepted February 6, 2015

DOI: $10.3892 / \mathrm{mmr} .2015 .3535$

\begin{abstract}
The aim of the present study was to identify biomarkers in osteosarcoma (OS) cell serum by antibody microarray profiling, which may be used for OS diagnosis and therapy. An antibody microarray was used to detect the expression levels of cytokines in serum samples from 20 patients with OS and 20 healthy individuals. Significantly expressed cytokines in OS serum were selected when $\mathrm{P}<0.05$ and fold change $>2$. An enzyme-linked immunosorbent assay (ELISA) was used to validate the antibody microarray results. Finally, classification accuracy was calculated by cluster analysis. Twenty one cytokines were significantly upregulated in OS cell serum samples compared with control samples. Expression of inteleukin-6, monocyte chemoattractant protein-1, tumor growth factor- $\beta$, growth-related oncogene, hepatocyte grwoth factor, chemokine ligand 16, Endoglin, matrix metalloproteinase-9 and platelet-derived growth factor-AA was validated by ELISAs. OS serum samples and control samples were distinguished by significantly expressed cytokines with an accuracy of $95 \%$. The results demonstrated that expressed cytokines identified by antibody microarray may be used as biomarkers for OS diagnosis and therapy.
\end{abstract}

\section{Introduction}

Osteosarcoma (OS) is the most common type of bone cancer and the incidence of OS is higher in adolescents (1). There are no obvious clinical signs at early stages of the disease only pain, swelling and joint dysfunction (1). OS is a disease

Correspondence to: Dr Zi-Qiang Zhu, Department of Orthopedics, The Second Affiliated Hospital of Xuzhou Medical College, 32 Meijian Road, Xuzhou, Jiangsu 221006, P.R. China

E-mail: zhuziiq@163.com

*Contributed equally

Key words: antibody microarray, osteosarcoma, cytokines, enzyme-linked immunosorbent assay, clustering analysis with high local aggressiveness and a tendency to metastasize to the lungs. Patients were amputated in early therapies but still $80 \%$ of them inevitably succumbed to lung metastasis (2). Thus, identification of molecular biomarkers that may provide precise diagnosis and treatment for OS are required.

Cytokines, a family of protein or micro-molecule polypeptides, are important in the regulation of cellular adhesion molecules and exhibit antitumor activity $(3,4)$. Cytokines can regulate cell growth and differentiation, and enhance immune responses to stimuli (5). In tumor pathogenesis, cytokines inhibit chemical carcinogenesis, lymphomas and breast cancer invasion (6-8). Li et al (9) showed that enhanced expression of bone morphogenetic protein in OS cells exerted inhibitory effects on their growth and migration. Elevated expression of chemokine (C-X-C motif) ligand 4 (CXCL4), CXCL6 and CXCL12 in the OS serum from infants was screened using an antibody microarray (5). This study aimed to identify other cytokines that may be biomarkers for OS diagnosis and therapy.

Protein expression profiling of serum obtained from patients and healthy individuals has been analyzed by enzyme-linked immunosorbent assay (ELISA), microRNA proofing and matrix-assisted laser desorption/ionization mass spectrometry (10-12). High-throughput screening has been demonstrated to be rapid and effective for protein profiling, which has been applied in a simple manner (13). Antibody microarray, a high-throughput method, has been widely used for protein expression profiling, such as profiling of cytokines and chemokines (14-16). Thus far, numerous potential biomarkers for cancer diagnosis have been identified in different cancer types by antibody microarray $(14,17,18)$.

In the present study, antibody microarray was used to identify the cytokines that were significantly expressed in OS and an ELISA method was used to confirm microarray results. Finally, clustering analysis of the expressed cytokines was performed for evaluation of classification accuracy.

\section{Materials and methods}

This study was approved by the ethics committee of The Second Affiliated Hospital of Xuzhou Medical College and Affiliated 
Huai'an Hospital of Xuzhou Medical College (Huaian, China) and all participants provided written informed consent.

Serum samples. Blood samples were obtained from 20 patients (between 2009 and 2013) with OS, including 10 male samples and 10 female samples at average age of 21.8 years. According to Dahlin's criteria (19), 12 cancer tissues were classified as osteoblastoma and the other samples were classified as chondroblastoma. Ten patients were detected with metastasis and the rest of the patients were negative for metastasis. In addition, 20 control serum samples were obtained from healthy individuals and blood donors including 10 male samples and 10 female samples at an average age of 23.9 years. Table I shows the characteristics of patients in the OS group.

Antibody microarray. A high-throughput antibody microarray AAH CYT-G2000, including AAH-CYT-G6, AAH-CYT-G7 and AAH-CYT-G8 was purchased from RayBiotech Inc. (Atlanta, GA, USA). One hundred and seventy-four antibodies have been immobilized on the slides in advance by the manufacturer. Cytokines in each serum sample were detected twice. Additionally, the negative control and the positive control for the cytokines were also detected twice in each serum. The slides were blocked in $3 \%$ (w/v) fat-free milk powder (blocking solution) followed by washing in phosphate-buffered saline (PBS). Then, $100 \mu \mathrm{l}$ serum samples (diluted four times with blocking solution) were incubated at $4^{\circ} \mathrm{C}$ overnight. Subsequently, slides were rinsed using PBST (containing PBS and 0.05\% Tween-20, $\mathrm{pH}$ 7.4) and PBS successively, four times for $5 \mathrm{~min}$. Then biotin-labeled antibodies were incubated for $2 \mathrm{~h}$ and washed with PBST for $30 \mathrm{~min}$. After drying, slides were incubated with fluorescent dye-conjugated streptavidin (RayBiotech Inc., Norcross, GA, USA) for $1.5 \mathrm{~h}$ and were scanned by an Axon GenePix 4000B scanner at $532 \mathrm{~nm}$ (Axon, Union City, CA, USA).

ELISA. ELISA was performed using commercially available kits from R\&D Systems (Minneapolis, MN, USA) according to the manufacturer's instructions. Absorbance was detected at $450 \mathrm{~nm}$ by a Bio-Rad model 680 microplate reader (Bio-Rad, Hercules, CA, USA). Duplicated experiments were performed for each sample.

Statistical analysis. Axon GenePix Pro 6.0 software (Axon, Union City, CA, USA) was used to analyze the scanning data and signals were normalized by positive signal values. Data were analyzed by one-way analysis of variance using SPSS 17.0 software (SPSS, Inc., Chicago, IL, USA). P $<0.05$ and fold change $>2$ were considered to indicate a statistically significant difference. The ratio of signal values from the sample channel to reference channel was calculated for each antibody spot.

In order to evaluate whether cytokine expression screening by antibody microarray could distinguish OS samples from control samples, unsupervised clustering analysis (20) of upregulated cytokines was performed using Cluster 3.0 (21), which was based on uncentered correlation and average linkage algorithms (22).
Table I. Clinical characteristics of the OS group and control group.

\begin{tabular}{lcc}
\hline & \multicolumn{2}{c}{ Number } \\
\cline { 2 - 3 } Clinical parameter & OS group & Control group \\
\hline Age (years) & 13 & 7 \\
$18-20$ & 11 & 9 \\
$21-25$ & & \\
Gender & 10 & 10 \\
Male & 10 & 10 \\
Female & & \\
Dahlin's criteria & 12 & - \\
Osteoblastoma type & 8 & - \\
Chondroblastoma type & & - \\
Metastasis & 10 & - \\
No & 10 & 20 \\
Yes & 20 & \\
Serum samples & &
\end{tabular}

OS, osteosarcoma.

\section{Results}

Screening of significantly upregulated cytokines using antibody microarray. Twenty serum samples from patients with OS and 20 from healthy individuals were analyzed using a microarray containing 174 antibodies. The sensitivity of the antibody microarray is $\mathrm{pg} / \mathrm{ml}$ and there were no cross reactions between cytokines. The background noise was low and signals from positive and negative control arrays were normal. Fig. 1 shows the expression levels of cytokines in OS samples compared with that in with control samples. The cytokines shown in Fig. 1 are listed in Table II. Expression levels of 21 cytokines were upregulated in OS samples when compared with control samples (Table II). The ratio of signal values from OS to control serum ranged from 2.15 to 12.14 fold. These results indicate clear differences in the cytokine expression profile between the OS and control groups.

ELISA validation of antibody microarray performance. Validation is important for interpreting and using antibody microarrays. The following nine cytokines shown in Table II were selected for ELISA analysis: interleukin 6 (IL-6), monocyte chemoattractant protein-1 (MCP-1), transforming growth factor- $\beta$ (TGF- $\beta$ ), growth-related oncogene (GRO), hepatocyte growth factor (HGF), CXCL-16, Endoglin, matrix metalloproteinase-9 (MMP-9) and platelet-derived growth factor (PDGF)-AA. Table III shows the cytokine expression profile analysis by antibody microarray and ELISA. ELISA results showed that expression levels of cytokines were significantly upregulated in OS samples compared with control samples $(\mathrm{P}<0.05)$, which was consistent with the microarray results. However, the ELISA concentration ratios 
Table II. Expressed cytokines identified in OS using antibody microarray.

\begin{tabular}{|c|c|c|c|c|c|}
\hline \multirow[b]{2}{*}{ No. } & \multirow[b]{2}{*}{ Cytokine } & \multicolumn{2}{|c|}{ Signal value } & \multirow[b]{2}{*}{ P-value } & \multirow[b]{2}{*}{ Fold change } \\
\hline & & Control group & OS group & & \\
\hline 1 & BMP-4 & 89 & 234 & 0.034 & 2.63 \\
\hline 2 & IL-10 & 324 & 698 & 0.041 & 2.15 \\
\hline 3 & IL-6 & 446 & 5421 & 0.011 & 12.14 \\
\hline 4 & MCP-1 & 1324 & 4673 & 0.023 & 3.53 \\
\hline 5 & TGF- $\beta$ & 564 & 1321 & 0.009 & 2.34 \\
\hline 6 & bFGF & 169 & 765 & 0.004 & 4.52 \\
\hline 7 & CCL-28 & 125 & 897 & 0.02 & 7.18 \\
\hline 8 & GRO & 2749 & 8754 & 0.006 & 3.18 \\
\hline 9 & HGF & 165 & 806 & 0.007 & 4.88 \\
\hline 10 & IL-8 & 234 & 786 & 0.021 & 3.36 \\
\hline 11 & TIMP-2 & 3215 & 12497 & 0.034 & 3.89 \\
\hline 12 & uPAR & 987 & 3215 & 0.008 & 3.26 \\
\hline 13 & VEGF-A & 123 & 798 & 0.045 & 6.49 \\
\hline 14 & VEGF-D & 132 & 1342 & 0.003 & 10.17 \\
\hline 15 & CXCL-16 & 1400 & 5414 & 0.018 & 3.87 \\
\hline 16 & Endoglin & 204 & 1189 & 0.003 & 5.82 \\
\hline 17 & IGF-II & 214 & 1023 & 0.041 & 4.78 \\
\hline 18 & MMP-1 & 234 & 1213 & 0.038 & 5.18 \\
\hline 19 & MMP-9 & 2315 & 15478 & 0.029 & 6.69 \\
\hline 20 & PDGF AA & 2984 & 32158 & 0.0004 & 10.78 \\
\hline 21 & PDGF-AB & 101 & 1078 & 0.048 & 10.71 \\
\hline
\end{tabular}

OS, osteosarcoma; BMP-4, bone morphogenetic protein 4; IL, interleukin; MCP-1, monocyte chemoattractant protein- 1 ; TGF- $\beta$, tumor growth factor- $\beta$; bFGF, basic fibroblast growth factor; GRO, growth-related oncogene; HGF, hepatocyte growth factor; TIMP-2, tissue inhibitor of metalloproteinase 2; uPAR, urokinase receptor; VEGF, vascular endothelial growth factor; CXCL-16, chemokine ligand 16; IGF-II, insulin growth factor II. MMP, matrix metalloproteinase; PDGF, platelet-derived growth factor.

Table III. Enzyme-linked immunosorbent assay validation of nine cytokines.

\begin{tabular}{|c|c|c|c|c|c|c|}
\hline \multirow[b]{2}{*}{ Cytokine } & \multicolumn{3}{|c|}{ Signal value } & \multicolumn{3}{|c|}{ ELISA concentration (pg/ml) } \\
\hline & Control group & $\begin{array}{l}\text { Osteosarcoma } \\
\text { (OS) group }\end{array}$ & $\begin{array}{l}\text { Ratio (OS } \\
\text { to control) }\end{array}$ & Control group & OS group & $\begin{array}{l}\text { Ratio (OS } \\
\text { to control) }\end{array}$ \\
\hline IL-6 & $446 \pm 82.23$ & $5421 \pm 236.98$ & 12.14 & $10.8 \pm 2.23$ & $21.65 \pm 9.34^{\mathrm{a}}$ & 2.00 \\
\hline MCP-1 & $1324 \pm 257.51$ & $4673 \pm 273.56$ & 3.53 & $380.65 \pm 65.66$ & $985.65 \pm 132.55^{b}$ & 2.59 \\
\hline TGF- $\beta$ & $564 \pm 128.46$ & $1321 \pm 142,87$ & 2.34 & $12.12 \pm 3.09$ & $43.14 \pm 10.11^{\mathrm{a}}$ & 3.56 \\
\hline GRO & $2749 \pm 874.44$ & $8754 \pm 486.66$ & 3.18 & $98.24 \pm 16.23$ & $221.23 \pm 45.98^{\mathrm{a}}$ & 2.25 \\
\hline $\mathrm{HGF}$ & $165 \pm 22.77$ & $806 \pm 45.66$ & 4.88 & $897.12 \pm 132.12$ & $2134 \pm 209.88^{b}$ & 2.38 \\
\hline CXCL-16 & $1400 \pm 285.63$ & $5414 \pm 853.65$ & 3.87 & $2.45 \pm 1.02$ & $12.23 \pm 4.56^{\mathrm{b}}$ & 4.99 \\
\hline Endoglin & $204 \pm 32.86$ & $1189 \pm 174.80$ & 5.82 & $3.88 \pm 2.32$ & $12.78 \pm 3.89^{\mathrm{a}}$ & 3.29 \\
\hline MMP-9 & $2315 \pm 443.74$ & $15478 \pm 5974.92$ & 6.49 & $456.12 \pm 89.24$ & $879.31 \pm 129.05^{\mathrm{a}}$ & 1.93 \\
\hline PDGF-AA & $2984 \pm 346.44$ & $32158 \pm 1679.54$ & 10.17 & $4321.93 \pm 736.88$ & $7865.45 \pm 628.00^{\mathrm{a}}$ & 1.82 \\
\hline
\end{tabular}

${ }^{\mathrm{a}} \mathrm{P}<0.05$ and ${ }^{\mathrm{b}} \mathrm{P}<0.01$, compared with the control group. The corresponding microarray results are also listed for comparison. Data are presented as the mean \pm standard deviation. IL, interleukin; MCP-1, monocyte chemoattractant protein- 1 ; TGF- $\beta$, tumor growth factor- $\beta$; GRO, growth-related oncogene; HGF, hepatocyte growth factor; CXCL-16, chemokine ligand 16; MMP-9, matrix metalloproteinase-9; PDGF-AA, platelet-derived growth factor-AA. 


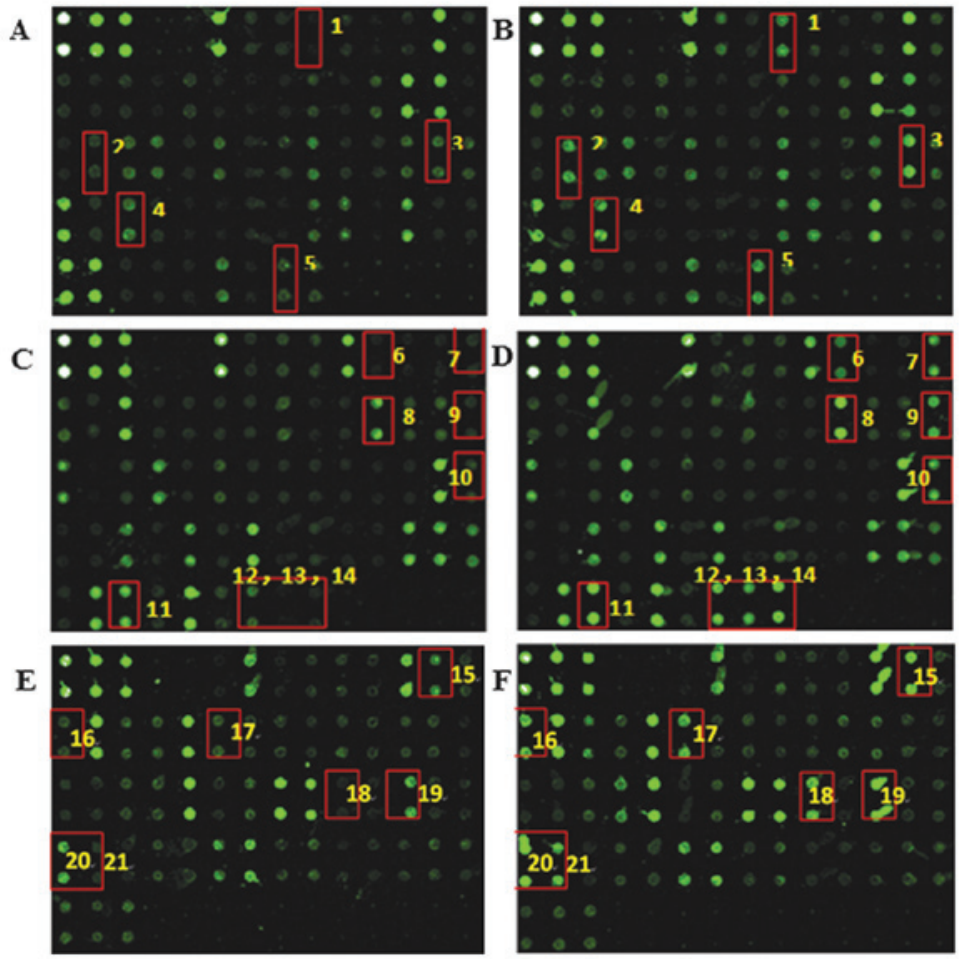

Figure 1. Scanned fluorescence image of an antibody microarray. Each antibody was printed in duplicate and test samples were incubated in the microarray. Subsequently, the microarray was incubated with biotin-labeled antibodies. Finally, the microarray was scanned by Axon GenePix at $532 \mathrm{~nm}$. (A) Results of the microarray AAH-CYT-G6 for samples in the normal control group; (B) results of the microarray AAH-CYT-G6 for samples in the osteosarcoma group; (C) results of the microarray AAH-CYT-G7 for samples in the normal control group; (D) results of the microarray AAH-CYT-G7 for samples in the osteosarcoma group; (E) results of the microarray AAH-CYT-G8 for samples in the normal control group; (F) results of the microarray AAH-CYT-G8 for samples in the osteosarcoma group. The number from 1 to 21 indicated 21 cytokines with upregulated expression in OS serum samples.

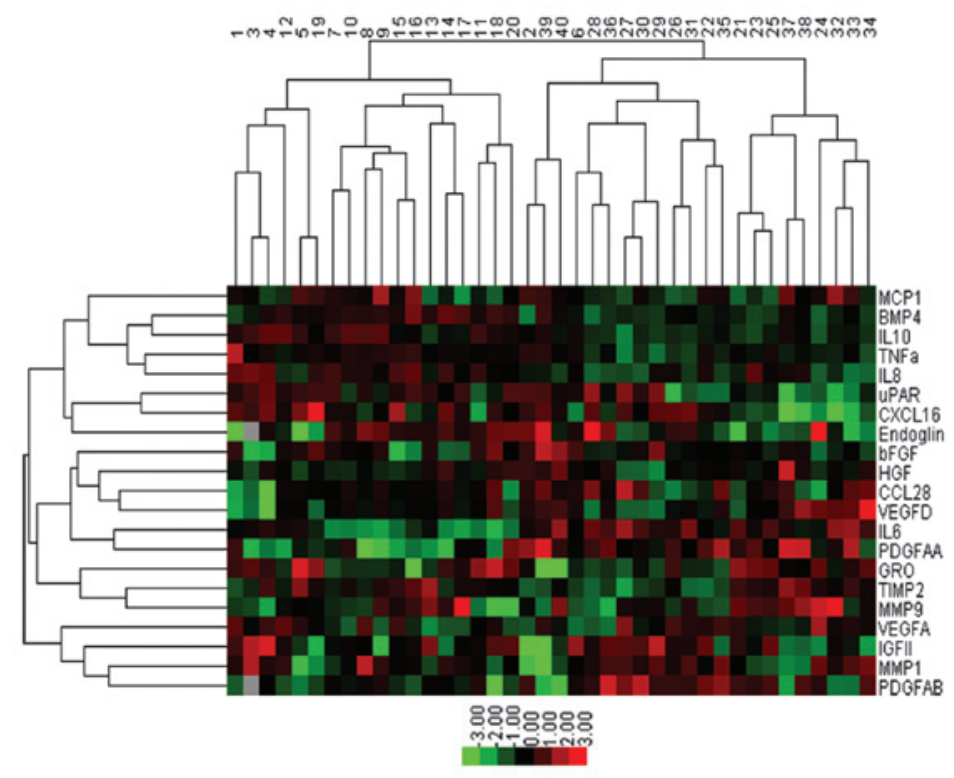

Figure 2. Cluster analysis of antibody binding profiles. Unsupervised cluster analysis was performed on 21 expressed cytokines based on average linkage. Nos. 1-20 represent samples in the control group and nos. 21-40 represent samples in the OS group. Each colored square represents one cytokine measurement. The color intensity of each square represents the relative protein binding. Red squares represent higher binding in OS samples. Green squares represent higher binding in control samples.

between the OS group and control group were not exactly the same as that in the microarray results. ELISA results showed that the concentrations of CXCL-16, TGF- $\beta$ and Endoglin were 4.99-, 3.56- and 3.29-fold greater than that in the control group, respectively. While antibody microarray results demonstrated that IL-6 and PDGF-AA had higher signal values compared with the control serum samples, 12.14- and 10.17-fold increases, respectively. 
Sample classification. Cluster analysis was performed on the 21 significantly upregulated cytokines $(\mathrm{P}<0.05)$ screened by antibody microarray (Fig. 2). The control group included 20 samples (nos. 1-20) and OS group included 20 samples (nos. 21-40). In total, 18 serum samples in the control group could be distinguished from OS group and all serum samples in the OS group could be distinguished from the control group. The accuracy of classification was $95 \%((18+20) / 40)$. The results showed that cytokine screening was able to distinguish OS patients from healthy individuals.

\section{Discussion}

In the present study, 21 cytokines were identified that were significantly upregulated in OS serum samples, compared with control serum samples. ELISA was then used to validate antibody microarray results. Thus, the antibody microarray method was observed to be reliable and significantly expressed cytokines may be used as biomarkers for OA diagnosis and therapy.In pediatric OS patients, antibody microarray identified elevated expression of CXC chemokines and the results were validated by ELISA (5). Similarly, antibody microarray has been used to screen biomarkers in other types of cancer, such as prostate (23), lung (24) and pancreatic cancer (25). The ratio of antibody microarray signals and ELISA concentrations from OS to control serum were not identical, however, the pattern of cytokine expression was the same. Microarrays can be affected by numerous factors, such as loss of antibody function, low antigen concentration and inconsistent antigen labeling (23).

This study identified 21 cytokines with upregulated expression in OS serum samples and expression of nine cytokines was validated by ELISA. Among these cytokines, MMP-9 has been reported to be expressed in childhood osseous OS (26). IL-6, HGF, Endoglin, TGF- $\beta$, PDGF-AA and MCP-1 have been reported to be associated with the pathogenesis of OS (27-32). CXCL16, a small protein that is a member of the CXC chemokine family (33), has been reported to be expressed in tumor cells and may be a prognostic marker in patients with colorectal cancer (34) and renal cell cancer (35). In the present study, CXCL16 was differentially expressed in OS samples compared with the control, and this was validated by ELISA. Conversely, CXCL16 did not show any differential abundance in pediatric OS patients compared with noncancerous disease controls in a study by Li et al (5). These opposite results may be due to the differences in serum samples and antibody microarrays. However, this requires confirmation in future studies.

To the best of our knowledge, this is the first study to show that GRO is upregulated in patients with OS. GRO, a member of the CXC chemokine subfamily, associated with tumorigenesis and metastasis (36), acted as growth factor in an autocrine manner in a human pancreatic cancer cell line (37) and mediated the invasion of breast cancer cells (38). GRO was also observed to contribute to the proliferation of esophageal cancer (36). Our results showed that expression levels of GRO were higher in OS samples than in control samples, which suggested that GRO may be a biomarker for OS diagnosis and therapy. However, further investigation is required for confirmation.

In conclusion, 21 upregulated cytokines were identified in OS samples using antibody microarray and ELISA to validate the results. Clustering analysis showed that expressed cytokines could distinguish patients with OS from healthy individuals. Thus, the expression of cytokines, screened by antibody microarray, may be used as biomarkers for OS diagnosis and therapy. However, the present data are limited to a relatively small group of patient samples and large experiments are required to investigate the association between cytokine expression and OS.

\section{References}

1. Ritter J and Bielack SS: Osteosarcoma. Ann Oncol 21: vii320-vii325, 2010

2. Wafa $\mathrm{H}$ and Grimer RJ: Surgical options and outcomes in bone sarcoma. Expert Rev Anticancer Ther 6: 239-248, 2006.

3. Zetter B: Adhesion molecules in tumor metastasis. J Exp Med 4: 219-229, 1993.

4. Wolf SF, Lee K, Swiniarski H, O'toole M and Sturmhoefel K: Cytokines and cancer immunotherapy. Immunol Invest 29: 143-146, 2000.

5. Li Y, Flores R, Yu A, et al: Elevated expression of CXC chemokines in pediatric osteosarcoma patients. Cancer 117: 207-217, 2011.

6. Smyth MJ, Thia KY, Street SE, et al: Differential tumor surveillance by natural killer (NK) and NKT cells. J Exp Med 191: 661-668, 2000.

7. Davidson WF, Giese T and Fredrickson TN: Spontaneous development of plasmacytoid tumors in mice with defective Fas-Fas ligand interactions. J Exp Med 187: 1825-1838, 1998.

8. Lin EY, Nguyen AV, Russell RG and Pollard JW: Colony-stimulating factor 1 promotes progression of mammary tumors to malignancy. J Exp Med 193: 727-740, 2001.

9. Li B, Yang Y, Jiang S, Ni B, Chen K and Jiang L: Adenovirus-mediated overexpression of BMP-9 inhibits human osteosarcoma cell growth and migration through downregulation of the PI3K/AKT pathway. Int J Oncol 41: 1809-1819, 2012.

10. Khan N, Cromer CJ, Campa M and Patz EF: Clinical utility of serum amyloid $\mathrm{A}$ and macrophage migration inhibitory factor as serum biomarkers for the detection of nonsmall cell lung carcinoma. Cancer 101: 379-384, 2004.

11. Lu J, Getz G, Miska EA, et al: MicroRNA expression profiles classify human cancers. Nature 435: 834-838, 2005.

12. de Noo ME, Tollenaar RA, Özalp A, et al: Reliability of human serum protein profiles generated with $\mathrm{C} 8$ magnetic beads assisted MALDI-TOF mass spectrometry. Anal Chem 77: 7232-7241, 2005.

13. Oh Y-H, Hong M-Y, Jin Z, et al: Chip-based analysis of SUMO (small ubiquitin-like modifier) conjugation to a target protein. Biosens Bioelectron 22: 1260-1267, 2007.

14. Zhou H, Bouwman K, Schotanus M, et al: Two-color, rolling-circle amplification on antibody microarrays for sensitive, multiplexed serum-protein measurements. Genome Biol 5: R28, 2004.

15. Huang R-P, Huang R, Fan Y and Lin Y: Simultaneous detection of multiple cytokines from conditioned media and patient's sera by an antibody-based protein array system. Anal Biochem 294: 55-62, 2001.

16. Wang CC, Huang RP, Sommer M, et al: Array-based multiplexed screening and quantitation of human cytokines and chemokines. J Proteome Res 1: 337-343, 2002.

17. Pitha-Rowe I, Petty WJ, Feng Q, et al: Microarray analyses uncover UBE1 L as a candidate target gene for lung cancer chemoprevention. Cancer Res 64: 8109-8115, 2004.

18. Tannapfel A, Anhalt K, Häusermann P, et al: Identification of novel proteins associated with hepatocellular carcinomas using protein microarrays. J Pathol 201: 238-249, 2003.

19. Dahlin DC and Coventry MB: Osteogenic sarcoma. A study of six hundred cases. J Bone Joint Surg Am 49: 101-110, 1967.

20. Johnson SC: Hierarchical clustering schemes. Psychometrika 32: 241-254, 1967.

21. de Hoon MJ, Imoto S, Nolan J and Miyano S: Open source clustering software. Bioinformatics 20: 1453-1454, 2004.

22. D'haeseleer P: How does gene expression clustering work? Nat Biotechnol 23: 1499-1501, 2005.

23. Miller JC, Zhou H, Kwekel J, et al: Antibody microarray profiling of human prostate cancer sera: antibody screening and identification of potential biomarkers. Proteomics 3: 56-63, 2003. 
24. Gao WM, Kuick R, Orchekowski RP, et al: Distinctive serum protein profiles involving abundant proteins in lung cancer patients based upon antibody microarray analysis. BMC cancer 5: 110, 2005.

25. Orchekowski R, Hamelinck D, Li L, et al: Antibody microarray profiling reveals individual and combined serum proteins associated with pancreatic cancer. Cancer Res 65: 11193-11202, 2005

26. Himelstein BP, Asada N, Carlton MR and Collins MH: Matrix metalloproteinase. 9 (MMP. 9) expression in childhood osseous osteosarcoma. Med Pediatr Oncol 31: 471-474, 1998.

27. Bian ZY, Fan QM, Li G, Xu WT and Tang TT: Human mesenchymal stem cells promote growth of osteosarcoma: Involvement of interleukin. 6 in the interaction between human mesenchymal stem cells and Saos. 2. Cancer Sci 101: 2554-2560, 2010.

28. Coltella N, Manara MC, Cerisano V, et al: Role of the MET/HGF receptor in proliferation and invasive behavior of osteosarcoma. FASEB J 17: 1162-1164, 2003

29. Postiglione L, Di Domenico G, Caraglia M, et al: Differential expression and cytoplasm/membrane distribution of endoglin (CD105) in human tumour cell lines: implications in the modulation of cell proliferation. Int J Oncol 26: 1193-1201, 2005.

30. Kloen P, Gebhardt MC, Perez-Atayde A, Rosenberg AE, Springfield DS, Gold LI and Mankin HJ: Expression of transforming growth factorbeta (TGF-beta) isoforms in osteosarcomas: TGF-beta3 is related to disease progression. Cancer 80: 2230-2239, 1997.

31. Sulzbacher I, Birner P, Trieb K, Träxler M, Lang S and Chott A: Expression of platelet-derived growth factor-AA is associated with tumor progression in osteosarcoma. Modern Pathol 16: 66-71, 2003.
32. Lin SK, Kok SH, Yeh FT, et al: MEK/ERK and signal transducer and activator of transcription signaling pathways modulate oncostatin M-stimulated CCL2 expression in human osteoblasts through a common transcription factor. Arthritis Rheum 50: 785-793, 2004

33. Lehrke M, Millington SC, Lefterova M, et al: CXCL16 is a marker of inflammation, atherosclerosis and acute coronary syndromes in humans. J Am Coll Cardiol 49: 442-449, 2007.

34. Hojo S, Koizumi K, Tsuneyama K, et al: High-level expression of chemokine CXCL16 by tumor cells correlates with a good prognosis and increased tumor-infiltrating lymphocytes in colorectal cancer. Cancer Res 67: 4725-4731, 2007.

35. Gutwein P, Schramme A, Sinke N, et al: Tumoural CXCL16 expression is a novel prognostic marker of longer survival times in renal cell cancer patients. Eur J Cancer 45: 478-489, 2009.

36. Wang B, Hendricks DT, Wamunyokoli F and Parker MI: A growth-related oncogene/CXC chemokine receptor 2 autocrine loop contributes to cellular proliferation in esophageal cancer. Cancer Res 66: 3071-3077, 2006.

37. Takamori H, Oades ZG, Hoch OC, Burger $M$ and Schraufstatter IU: Autocrine growth effect of il-8 and gro [alpha] on a human pancreatic cancer cell line, capan-1. Pancreas 21: 52-56, 2000.

38. Li J and Sidell N: Growth. related oncogene produced in human breast cancer cells and regulated by Syk protein. tyrosine kinase. Int J Cancer 117: 14-20, 2005. 